\title{
EL PODER DE UNA RED FEMENINA. FAMILIA, VIDA Y MUERTE DE LUISA DE VELASCO (S. XVII)'
}

\section{THE POWER OF A FEMININE NETWORK. THE FAMILY, LIFE AND DEATH OF LUISA DE VELASCO}

\author{
Carmen María Fernández Nadal \\ Universitat Jaume I
}

\section{RESUMEN}

La documentación, generada por la muerte de Luisa de Velasco, permite sacar a la luz un entramado de relaciones entre mujeres de la élite, una parte de ellas servidoras en la corte española en el siglo XVII. Unidas por la amistad forjada en palacio y por sus lazos de sangre, gestionaron los intereses hereditarios de los Fernández de Velasco. Además, en este caso, podemos reconstruir y analizar una red que desde la Corte madrileña conectaba otros espacios de poder de la monarquía de los Austrias.

Palabras clave: mujeres de la élite, damas, marquesa de Quirra y Nules, marquesa del Fresno, virreinas, condesa de Paredes, nobleza.

\section{ABSTRACT}

Documentation produced after Luisa de Velasco's death has enabled the discovery of a network of relationships among elite women, some of whom had been working as servants in the Spanish royal court in the seventeenth century. These women, who were bound to each other by a friendship cemented at the palace and by their blood ties, managed the hereditary interests of the Fernández de Velasco family. The documentation also enables us to reconstruct and analyse this network, which connected other areas of power of the Spanish Habsburg monarchy from the Court in Madrid.

Keywords: elite women, servants, Marquise of Quirra and Nules, Marquise of El Fresno, vicereines, Countess of Paredes, nobility. 
Las tierras extremeñas de Berlanga vieron nacer a Luisa de Velasco, solar de su linaje. Pero fue la ciudad mediterránea de Valencia, lejos de su madre, de su hermana y de sus hermanos donde dio su último suspiro a los 37 años $^{2}$. Allí había llegado tras casarse con el marqués de Quirra. Rodeada de la familia de éste, de sus criados y de la virreina Paredes vivió sus últimas horas en la casa de la calle Murviedro ${ }^{3}$.

Unas almorranas gangrenadas la habían debilitado y, aunque parecía recuperada, la noche del 29 de julio de 1674 se sintió indispuesta. Intentaron aliviarla aplicándole algodones de algalia en las orejas, pero el olor le causó "un trastorno" del que ya no se recuperó. Con el pulso apagado y -una respiración muy cansada- llegó el nuevo día sin que se apreciara mejoría, fue el momento de avisar al conde del Real. Luisa le pidió ver a su tío, Alfonso de Calatayud, para ajustar sus últimas voluntades, lo que le comunicó, con la intención de regresar al día siguiente para finalizar su testamento; además, quiso ver al rector de San Esteban, que regresó de inmediato de la playa para confesarla. Los médicos, sin embargo, no vieron la urgencia de que comulgase y lo postergaron para aquel último día del mes, que fue también el suyo ${ }^{4}$.

Las carreras de criados y familiares anunciaban lo peor aquella trágica mañana de verano. Ante la grave situación, contó después el conde del Real, cómo su sobrino Vicente y doña Inés habían caído desmayados por la

1 Este trabajo se está realizando dentro del proyecto de investigación: De pequeños hidalgos a nobles titulados. Riquezas, poder y redes clientelares de la nobleza mediterránea (PI. 1A2014-13). Investigador principal: Carmen Corona. Universitat Jaume I (2015-2017).

2 Archivo Histórico Nacional de Madrid [AHN], OM, Pruebas Casamientos Montesa, exp. 195.

3 Archivo Histórico de la Nobleza [AHNOB], FRÍAS, C., 404, D. 1. Copia de la carta del conde del Real a su hermano don Antonio de Calatayud, del Supremo y Real Consejo de Aragón.

$4 \mathrm{lbídem}$. El cirujano Gerónimo Rodríguez atendió a la marquesa en la enfermedad: $A H N O B$, Frías, C. 1414, D. 5. Testamento de doña Luisa de Velasco de 31 de julio de 1674. 
impresión del momento, que él describió como "un terror" ${ }^{\prime \prime}$. Fue la condesa de Paredes la que tomó la decisión de avisar a su madre de lo acontecido, a través de su confesor, el Padre Nájera de la compañía de Jesús ${ }^{6}$.

Se iniciaba a partir de aquí un proceso complejo para clarificar la herencia de la joven que nos ha permitido no sólo analizar este aspecto, sino también reconstruir la red femenina en la que participaba Luisa de Velasco y en la que destacan relevantes damas, los sujetos protagonistas de esta investigación. A continuación veremos cómo se relacionaban y la importancia de las gestiones que ellas personalmente realizaban en beneficio de sus respectivos núcleos familiares.

Desde el epicentro de la monarquía la red conectaba otros espacios de poder y áreas regionales. Familias unidas por intereses comunes de reciprocidad intercambian favores entre la corte madrileña y el virreinato valenciano a finales del siglo XVII, cuando la regencia de la reina Mariana de Austria tocaba a su fin.

\section{Vida y familia de Luisa de Velasco, marquesa de Quirra y Nules (Ber- LANGA, 1636 CA.- VALENCIA, 1674)}

En 1660, los primeros marqueses del Fresno acordaron para la pequeña de sus descendientes un matrimonio con el marqués de Quirra y Nules, Joaquín Carroz de Centelles (1615 ca.-1674), un noble valenciano con un importante patrimonio y título en Cerdeña. El viudo había perdido a los hijos nacidos de sus dos primeros matrimonios y, seguramente, buscó con este tercer enlace el ansiado heredero que finalmente no llegó. Los catorce años de unión estuvieron protagonizados por los problemas económicos del marqués y sus luchas ante los tribunales para garantizar la restitución dotal de su esposa y su voluntad hereditaria. Fue un tema arduo que se complicó con el paso de los años y la falta de descendencia ${ }^{7}$.

5 AHNOB, FRÍAS, C., 404, D. 1. Copia de la carta del conde del Real a don Antonio de Calatayud. Doña Inés debe ser la esposa del conde.

6 Ibídem.

7 Sobre el marquesado de Nules y Quirra y la vida del Joaquín Carroz de Centelles (1615 ca.1674) y sus tres matrimonios véase el siguiente trabajo: FERNÁNDEZ NADAL, Carmen María: "Vínculos parentales del marquesado de Quirra y Nules (siglo XVII)" (en prensa). 
Este acuerdo matrimonial unía a una noble castellana con un noble titulado de la periferia. Aunque el marqués tenía problemas de liquidez poseía un relevante patrimonio tanto en Valencia como, sobre todo, en Cerdeña que lo convertía en un buen candidato. Suponía, además, para los Fernández de Velasco, extender sus redes de influencia hasta el Mediterráneo. A él le daba la oportunidad de emparentar con uno de los linajes castellanos más importantes $y$, además, con una buena posición en la Corte, en aquellos convulsos años de la regencia. Al mismo tiempo, la dote, aportada por la familia de la novia, estaba destinada a solventar, en parte, los problemas económicos de su Casa. Como sucedía con otros muchos linajes, el marqués de Quirra tenía la mayor parte de su patrimonio vinculado, y sufría para poder saldar sus deudas.

Podemos identificar una red femenina en la que participaba la marquesa de Quirra y Nules, con dos núcleos geográficos claramente establecidos: la corte madrileña y la corte virreinal valenciana. La principal, la de nacimiento, estaba conformada por una maraña de conexiones en la que su madre, la marquesa Catalina de Velasco, sobresalía como una figura femenina esencial. Su larga vida y su trayectoria vital y familiar ayudaron al sostenimiento de esta estructura de relaciones ${ }^{8}$.

\subsection{La constitución de la red femenina en la Corte}

El entramado del que participaba Luisa de Velasco se caracterizaba por estar plagado de servidores áulicos, aunque ella no ejerció cargo alguno. Fueron sus hermanos mayores los favorecidos en este sentido, continuando con una tradición familiar que perduró en el tiempo. Si nos detenemos a examinar a las mujeres del linaje, comprobamos las sucesivas generaciones de meninas o damas en las diferentes casas de la reina, tanto por vía paterna como materna.

El ejercicio de este puesto cortesano las convertía en valiosas informadoras de todo lo que ocurría en las estancias femeninas de palacio. A una edad temprana eran educadas directa e indirectamente en el manejo de la información social y política, a conducirse tanto en los espacios privados como públicos. Eran sujetos que tenían la capacidad de transmitir aspiraciones y deseos del exterior $y$, al mismo tiempo, comunicar información relevante, a través de sus cartas y de sus breves encuentros con sus familiares?.

8 Véase, Figura 2.

9 LÓPEZ-CORDÓN CORTEZO, M. Victoria (2009): "Las mujeres en la vida de Carlos II". RIBOT GARCÍA, Luis A. (coord.): Carlos II: el rey y su entorno cortesano. Centro de Estudios Europa Hispánica, Madrid. pp. 109-140, en especial, pp. 116-118. LÓPEZ-CORDÓN CORTEZO, M. 
La madre (Catalina de Velasco) y la tía (Mariana, fallecida tempranamente) de Luisa habían ocupado el puesto a principios de siglo, al servicio de Isabel de Borbón, como antes lo había hecho su bisabuela, Mariana Enríquez. Lo propio hicieron a las órdenes de Mariana de Austria en tiempos de Felipe IV, su hermana mayor, Juana Francisca de Córdoba y Velasco y la que se convertiría en su cuñada, Antonia de Luna la la postre condesa de Peñaranda) ${ }^{10}$. Primas, como Magdalena de Velasco (hija de su tío el séptimo conde de Fuensalida) y demás parentela, ejercieron el mismo puesto: las Manrique de Lara (condesas de Paredes), o las Velasco (Catalina y Leonor, condesas de Siruela) ${ }^{11}$.

En su infancia y juventud gestaron amistades que perduraron en el tiempo. Emparentadas y unidas por aquella vivencia común, en aquellos primeros años cruciales, estructuraron una red de damas que pudieron utilizar posteriormente para favorecerse. Además de estar al tanto de los detalles personales, de la vida de todos aquellos que las rodeaban, trataban temas

V. (2003): "Entre damas anda el juego: las camareras mayores de Palacio en la edad moderna". Cuadernos de Historia Moderna. Anejos, N. 2, 2003, pp. 123-152. OLIVÁN SANTALIESTRA, Laura (2008): "La dama, el aya y la camarera: Perfiles políticos de tres mujeres de la Casa de Mariana de Austria". MARTíNEZ MILLÁN, José y MARÇAL LOURENÇO, Maria (coord.): Las relaciones discretas entre las Monarquías Hispana y Portuguesa: Las Casas de las Reinas (siglos XV-XIX), 3 vols., vol. 2, Polifemo, Madrid, pp. 1301-1356.

MAREK, Pavel (2011): "Luisa de las Llagas. La abadesa de las Descalzas y el proceso de la comunicación política y cultural entre la corte real española y la imperial", Pedralbes, 31, pp. 47-90. MAREK, Pavel (2008): "Las damas de la emperatriz María y su papel en el sistema clientelar de los reyes españoles. El caso de María Manrique de Lara y sus hijas" MARTíNEZ MILLÁN, José y MARÇAL LOURENÇO, Maria (coord.): Las relaciones discretas entre las Monarquías Hispana y Portuguesa: Las Casas de las Reinas (siglos XV-XIX), 3 vols., vol. 2, Polifemo, Madrid, pp. 1003-1036.

10 Aunque en esas fechas Antonia de Luna era la marquesa del Fresno por su matrimonio con Pedro Fernández de Velasco, hijo de los primeros marqueses del Fresno, a lo largo del texto, cuando se cita a la marquesa del Fresno, se está haciendo referencia a Catalina de Velasco, marquesa viuda.

Sobre Antonia de Luna, véase: FERNÁNDEZ NADAL, Carmen María (2011): "Damas, poder y diplomacia en el siglo XVII: Antonia de Luna, Luisa de Ayala y María Teresa Ronquillo". Dossiers Feministes, 15, pp. 101-126.

11 Sobre este punto véase el siguiente trabajo FERNÁNDEZ NADAL, Carmen María: "El mercado cortesano: Las redes parentales de las Velasco en el XVII" (en prensa). 
políticos de la mayor relevancia con otros miembros de su entorno, tanto mujeres como hombres, padres, o hermanos.

Las relaciones que se confeccionaban entre las estancias áulicas suponían la creación de vínculos que tenían su reflejo en otros espacios de poder, donde también nacían alianzas o se consolidaban. Núcleos de influencia conectados por los eslabones de la cadena y por los intereses compartidos o necesariamente correspondidos.

De esta red familiar de mujeres, consolidada entre los muros del Alcázar, vamos a destacar la relación instituida entre las Fernández de Velasco y las Manrique de Lara. Dejando a un lado los antepasados comunes y remotos de ambos linajes, y centrándonos en las últimas generaciones, podemos comprobar la relación de parentesco que unía a Catalina de Velasco y $M^{a}$ Inés Manrique de Lara ${ }^{12}$. El tratamiento que utilizaban era el de amigas y "primas", pues eran primas segundas. La condesa citaba a Luisa como su "sobrina" y al resto de hijos de la marquesa como sus "sobrinos", pues eran sus sobrinos terceros. Ambas mujeres, Catalina y $M^{a}$ Inés, compartían bisabuelos: Juana Manrique, hija de los condes de Paredes, y Fadrique Enríquez Girón ${ }^{13}$.

Aunque estas dos mujeres no llegaron a coincidir como damas de la reina en el mismo período cronológico, la condesa de Paredes sí que lo hizo con la hija mayor de la marquesa del Fresno, con Juana de Córdoba y Velasco ${ }^{14}$. Años después, la condesa coincidiría igualmente con la hija menor, Luisa de Velasco, esta vez en Valencia.

\subsection{Engrandecimiento y consolidación de la red en Valen- cia. Las amigas de la marquesa de Quirra}

Para instituir consolidadas redes de alianza y dependencia era fundamental que los miembros de la familia, en este caso nobiliaria, participaran en diferentes esferas jerárquicas, que les permitieran aproximarse a patrones. De esta manera se constituían como piezas esenciales de las relaciones, a veces, entre iguales, también, verticales, de lealtad y asisten-

12 Sólo contamos con las cartas que escribía la condesa de Paredes durante sus últimos meses en Valencia pues hasta la fecha no hemos tenido la fortuna de encontrar la correspondencia de la marquesa con su "prima".

$13 A H N O B$, FRÍAS, C.,1414, D. 2. Correspondencia de la condesa de Paredes a la marquesa del Fresno (la mayor).

14 Archivo General de Palacio (Madrid) [AGP], Personal, caja 670, exp. 51. 
cia; un diálogo complejo que podía suponer intercambios desiguales, de dependencia y dominación ${ }^{15}$.

En este caso, vemos como había diferentes estrategias para ampliar y consolidar las redes clientelares y de alianza. En la casa de la reina conseguían fortalecer las relaciones familiares con lazos de amistad, y al mismo tiempo, la propia Corte era también escenario de ajustes matrimoniales que servían para ampliar su red de influencia. La parentela de Quirra, representada por el conde del Real fue, seguramente, el brazo ejecutor de aquel acuerdo entre una cortesana rama menor de los Fernández de Velasco y una antigua casa nobiliaria de la periferia, con un marqués que decía ser la cabeza de los Carroz y los Centelles ${ }^{16}$. Y aunque el origen de su sangre pudiera ser discutido, no lo eran los vínculos y los títulos que ostentaba, tanto en el reino de Valencia como en la isla de Cerdeña ${ }^{17}$.

La joven se trasladó a Valencia, acompañada por algunos de sus criados que fielmente habían servido a su $\mathrm{Casa}^{18}$. Éstos se unieron a los que ya trabajaban para el marqués. Una vez conformado su nuevo hogar, en la ciudad mediterránea del Turia, empezó a tejer su propia red de amistad basada, sobre todo, en sus relaciones familiares y en la parentela de su esposo, los Calatayud ${ }^{19}$. Y, al mismo tiempo, se incorporó al entramado clientelar en el que participaba su esposo. Aunque es difícil identificar a todos los miembros del grupo, a continuación mencionamos a aquellos que estuvieron más cerca de ella en sus últimos años o ayudaron a gestionar su herencia en el período inmediatamente posterior a su muerte.

A partir de 1668, Luisa de Velasco coincidirá con la condesa de Paredes, Inés María Manrique de Lara, y su esposo el virrey Vespasiano Gonza-

15 Sobre esta línea de investigación han sido fundamentales los trabajos y las obras coordinadas de Imízcoz o Martínez Millán, entre los que podemos destacar los siguientes y otros que señalaremos más adelante: Imízcoz Beunza, José M. (2006): "Las redes sociales de las élites, conceptos, fuentes y aplicaciones". Soria Mesa, Enrique, Bravo Caro, Juan Jesús y Delgado Barrado, Miguel (Coord.): Las élites en la época moderna: La monarquía española, vol. 1, Universidad de Córdoba, Córdoba, pp. 77-112; Martínez Millán, José (1989): “Élites de poder en tiempos de Felipe II (1539-1572)". Hispania: Revista española de historia, núm. 171, pp. $111-149$.

16 AHN, Consejos, leg. 18826, $\mathrm{n}^{\circ}$ 18. Madrid, 7 de diciembre de 1647.

17 AHNOB, FRÍAS, C., 404. Capítulos matrimoniales, Madrid, el 9 de marzo de 1660. Y poder del marqués de Quirra y Nules a su primo el tercer conde del Real, mayordomo de la reina para tratar y concertar los capítulos matrimoniales: Valencia, 22 de febrero de 1660.

18 AHNOB, FRÍAS, C., 404, D. 1.

19 Véase, Figura 1. Árbol genealógico de la familia de los condes del Real. 
ga -que utilizó tanto el apellido como el título de la dama. La fidelidad de los condes a Mariana de Austria les valió aquel relevante puesto cuando la situación en la Corte era cada vez más complicada entre Nithard y don Juan José de Austria. El nuevo virrey inició su andadura con un temprano éxito al reducir la cuadrilla del bandido valenciano Josep Artús. El bandidaje fue una de las principales problemáticas que tuvo que enfrentar ${ }^{20}$.

Gracias al testamento de la marquesa de Quirra sabemos que tanto la virreina como sus hijas, Josefa e Isabel, se encontraban dentro de su círculo más íntimo en Valencia ${ }^{21}$. Junto a ellas estaban también Mariana Ladrón y Silva (n. 1650), cuarta condesa de Sinarcas (primera marquesa de Sot y condesa consorte de Anna) ${ }^{22}$. Precisamente el año (1660) en el que Luisa había iniciado su vida de casada coincidió con el ingreso de Mariana como dama menina de la reina -cuando su abuela, Mariana de Velasco Ibarra, todavía permanecía en palacio como dueña de honor. Seis años después, dejó su puesto para casarse con el noble aragonés Juan de Palafox, hijo del marqués de Ariza $(1666)^{23}$; pero esta unión duró poco, y la condesa volvió

20 Vespasiano Gonzaga recibió el nombramiento a finales de 1667: Mateu Ibars, Josefina (1963): Los virreyes de Valencia. Ayuntamiento de Valencia, Valencia, p. 296. GARCÍA MARTíNEZ, Sebastián (1991): Valencia bajo Carlos II. Ayuntamiento de Villena, Villena, pp. 189194. KALNEIN, ALBRECHT Graf von (2001): Juan José de Austria en la España de Carlos II. Milenio, Lleida, pp. 110-111.

Don Vespasiano pertenecía a la Casa de Mantua: Maura Gamazo, Gabriel (1911): Carlos II y su Corte, Ensayo de reconstrucción biográfica, Tomo I, Madrid, p. 548.

CALLADO ESTELA, Emilio (2004): "Cameros versus Manrique de Lara. Historia de un desencuentro entre el Arzobispo y el Virrey de Valencia en el marco de las tensiones jurisdiccionales Iglesia-Corona (1669)". ARANDA PÉREZ, Francisco José (Coord.): La declinación de la monarquía hispánica. VII Reunión Científica de la Fundación Española de Historia Moderna. Universidad de Castilla La Mancha, Cuenca, pp. 661-676.

21 AHNOB, Frías, C. 1414. D. 5. Testamento de Luisa.

22 Aunque existe confusión en la fecha de la concesión, parece que fue otorgada en el año de 1666, coincidiendo con su matrimonio, por los servicios de ella en virtud de la posesión y herencia que tenía sobre estos estados: $A H N$, Consejos, 22090. Después le sucedería su hermana, la condesa Lucrecia Ladrón, con la que a veces se confunde a la anterior. A la muerte de Lucrecia, el 13 de septiembre de 1729, se inició la lucha por la sucesión al fallecer sin descendencia. $A H N O B$, Frías, C. 1414. D. 5. Testamento de Luisa.

23 AGP, Personal, caja 670, exp. 51: Mariana de Velasco lbarra era condesa de Sinarcas consorte por su matrimonio con Juan Ladrón y Pallás, segundo conde de Sinarcas. Sabemos que Mariana de Velasco Ibarra ocupó el puesto hasta su muerte en 1668 gracias al artículo de Novo Zaballos, José Rufino (2008): "La Casa real durante la regencia de una reina: Mariana de Austria". Martínez Millán, José y Marçal Lourenço, Maria (coord.): Las relaciones discretas 
a contraer matrimonio con el valenciano Antonio Fernando Pujadas Borja Coloma (conde de Anna). Este último aparece, a su vez, como albacea de la marquesa de Quirra ${ }^{24}$.

Otra de las amigas Luisa fue la hermana del conde de Anna, doña Guiomar Coloma y Castellví, esposa del gobernador de Valencia, José Castellví Alagón. Éste había sido menino del rey Carlos II y, en aquellas fechas, era gobernador de Valencia -más tarde, intentó ocupar el puesto de Vespasiano Gonzaga como virrey de Valencia (1675), y aunque no lo consiguió, a finales de siglo logró el virreinato de Mallorca ${ }^{25}$.

Doña Guiomar también había tenido una hermana en palacio, María Coloma (dama menina, en 1656), que aparece en la correspondencia consultada como la condesa de Puñonrostro (casó en 1664). Tras la muerte de la marquesa de Quirra, su criada doña Ana Álvarez actuará como intermediaria entre esta condesa y la marquesa del Fresno. Ambas posiblemente debieron conocerse en la Corte ${ }^{26}$. Precisamente, María Coloma había coincidido en palacio con su futura cuñada, la condesa de Sinarcas, una de las amigas, ya citadas, de la marquesa Luisa de Velasco. Ésta y su hermana Lucrecia habían ejercido como damas meninas de Mariana de Austria en periodos distintos y sucesivos (1660-1666 y 1669-1674) ${ }^{27}$.

entre las Monarquías Hispana y Portuguesa: Las Casas de las Reinas (siglos XV-XIX). 3 vols. Vol.

2, Polifemo, Madrid, pp. 483-547, véase: p. 504.

24 AHNOB, FRÍAS, C., 1414. D. 5. Testamento de Luisa.

25 Doña Guiomar Coloma, hija del conde de Elda, Juan Andrés Coloma (Joan Andreu) y la condesa de Anna, Isabel Pujadas de Borja, era la hermana de Francisco Coloma (que heredó finalmente los títulos) y de Antonio Fernando Pujadas Borja Coloma, conde de Anna.

FELIPO ORTS, Amparo (2007): "El testament del marqués de Villatorcas i la disputa del comte de Cervelló per l'heréncia paterna. Una altra conseqüencia de l'exili austracista". Aguaits, 24-25, pp. 97-121. Sobre don José de Castellví, véase pp. 98-101. CHIQUILLO PÉREZ, Juan A. (1991): "La nobleza austracista en la guerra de Sucesión. Algunas hipótesis sobre su participación". Estudis: Revista de historia moderna, n 17, pp. 15-148: Sobre los Coloma véase pp. 144-145.

26 AGP, Personal, caja 670, exp. 51. Conocida como María Coloma en palacio, aparece posteriormente como María Manuela Coloma. Era hija del conde de Elda y, por lo tanto, hermana de: Guiomar, Antonio Fernando, Francisco y Joseph. Tras la muerte sin descendencia de los herederos mayores y del hijo de Francisco Coloma (Francisco Coloma y Leyva, además austracista) será su hijo Gonzalo Joseph Arias-Dávila Coloma el heredero de los títulos de la familia.

VILAR Y PASCUAL, Luis (1860): Diccionario Histórico Genealógico y heráldico de las familias Ilustres de la monarquía española. Tomo III, Imprenta de D. F. Sánchez, Madrid, pp. 26-28. 
Guiomar y Mariana estaban emparentadas y juntas, seguramente, intercambiaban visitas y confidencias con Luisa de Velasco. Allí, en Valencia, todas aquellas señoras debieron forjar su amistad. En el grupo, además, corresponde incluir a Inés María Chaves y Mendoza, la tercera esposa del cuarto conde del Real. Lazos familiares unían igualmente a los condes de Sinarcas y los condes del Real ${ }^{28}$.

No es de extrañar que Inés María Chaves formara parte del círculo de la marquesa, más allá de las relaciones de amistad con las otras damas, ésta formaba parte de la parentela de su esposo. Incluso si profundizamos en estas familias vemos como los miembros de los condados de Sinarcas, Anna y del Real y el marquesado de Ariza se entrelazan.

El conde de Anna, Antonio Fernando Pujadas, era el nieto de Ana $M^{a}$ Mateu, que tras enviudar ${ }^{29}$ y dejar a su hija, Isabel, como heredera del condado, volvió a contraer matrimonio con el tercer conde del Real (muere en enero de 1674) ${ }^{30}$. Por lo tanto, el citado conde de Anna, Antonio Fernando, esposo de la condesa de Sinarcas, era también sobrino del cuarto conde del Real.

27 AGP, Personal, caja 670, exp. 51. Lucrecia aparece en palacio como hija del duque de Villahermosa, ella como su hermana eran hijas de Gaspar Ladrón, conde de Sinarcas y María de Silva, hija de los marqueses de Orani, que se había vuelto a casar con el duque de $\mathrm{Vi}$ llahermosa. Justo en abril de 1674, Lucrecia había salido de palacio para casarse con el hijo del duque de Linares. Lucrecia heredó el título de su hermana al morir ésta sin descendencia. Finalmente, por falta de descendencia, el condado de Sinarcas pasará después al ducado de Villahermosa.

28 Los descendientes de María Ladrón lucharán por los estados de Chelva y Sinarcas a la muerte sin descendencia de las hijas de Gaspar Ladrón: Primero, Mariana y, después, Lucrecia. El condado de Chelva ya llevaba tiempo en secuestro por litigio: Real Academia de la Historia [RAH], sign. 25, fo 24 v, Casa de Villanova. Con acceso a través de la Biblioteca digital de la Real Academia de la Historia: http://bibliotecadigital.rah.es/

CATALÁ SANZ, Jorge Antonio (1995): Rentas y patrimonios de la nobleza valenciana en el siglo XVIII. Siglo Veintiuno, Madrid, p. 19. Los Zapata de Calatayud unirán en el XVIII, tras la resolución de los pleitos, el condado de Sinarcas al del Real para después ser absorbidos por el ducado de Villahermosa.

29 Ana $M^{a}$ Mateu se había casado en primeras nupcias con Juan Pujades el segundo conde de Anna: $R A H$, sign. 9/304, f० 131. Familia Matheu y $R A H$, sign. 9/320, fo 61 v, Familia Pujades.

30 Ana $M^{a}$ Mateu dejó como heredero universal a su hijo don Ximén Pérez de Calatayud su hijo primogénito y futuro cuarto conde del Real. En su testamento de 1657 estableció como albaceas a don Ximén Pérez de Calatayud, a don Joan Andreu conde de Elda y Anna (el marido de su primera hija, Isabel) y a don Alonso Calatayud, los tres aceptaron el encargo: Archivo 
Ximén Pérez de Calatayud, conde del Real y de Villamonte, contrajo matrimonio en tres ocasiones antes de heredar a su padre: la primera con Francisca Ladrón (hija del segundo conde de Sinarcas ${ }^{31}$ ); después con Teresa Palafox y Cardona (hija de los marqueses de Ariza) ${ }^{32}$; y por último, en 1670 lo hizo con Inés María de Chaves, la hija doña Anna Isabel de Mendoza, ya fallecida, y don Juan de Chaves Sotomayor (clérigo de menores órdenes, caballero de la orden de Alcántara). La unión fue gestionada, por parte de la novia, por Mariana de Velasco y Osorio, marquesa de Salinas, tía de la joven ${ }^{33}$.

En el apartado de amistades de la marquesa no debemos dejar de destacar dos figuras de la familia Calatayud: don Alfonso de Calatayud ${ }^{34}$, primo del marqués de Quirra, y su mujer, Úrsula Ciurana de Calatayud. La

del Reino de Valencia [ARV], Real Justicia, vol. 790 fol. 140-141v. Cláusula de la herencia del último testamento de Ana $M^{a}$ Mateu condesa del Real, nombrando heredero a su hijo. Testamento realizado en su casa en la calle de la Señora de la Alcudia en Valencia el 13 de enero de 1657 ante Nicolau Juste.

El tercer conde del Real murió en enero de 1674.

31 Francisca Ladrón Ferrer y Velasco, era la hija de Juan Ladrón, segundo conde de Sinarcas y de Mariana de Velasco (hermana de la marquesa de Salinas): $R A H$, sign. 9/320, fo $9 \mathrm{v}$.

32 Para la joven era su primer matrimonio. Su padre era D. Juan Ximénez de Urrea Doris Blanes de Palafox, marqués de Ariza, consejero de Aragón y su madre María Felipa de Cardona: ARV, Justicia, Justicia Civil, Manaments y Empares, año 1662, L1, mano 1, fol. 20 y 24.

33 En el tercer matrimonio en nombre del conde del Real y de Villamonte actuó Joseph Cañizares. Doña Inés, por su parte, estuvo representada por doña Mariana de Velasco y Osorio, marquesa de Salinas y su tía por parte de su padre, don Juan de Chaves Sotomayor, clérigo de menores órdenes, caballero de la orden de Alcántara y vecino de Ruanes villa de Trujillo (Extremadura). La marquesa con el poder de su hermano político fue la encargada de capitular, concluyendo las negociaciones entre ambas familias. La madre de doña Inés, doña Anna Isabel de Mendoza, ya había fallecido. El matrimonio se concertó para cuatro meses después de firmadas las capitulaciones. El conde del Real garantizó la posible restitución de la dote, con la herencia ya recibida por la muerte de su madre, un mayorazgo que ya poseía y con lo que esperaba heredar de su padre el conde del Real: ARV. Justicia, Justicia Civil, Manaments y Empares, año 1676, L1, mano 1, fol. 22-31v. Capítulos matrimoniales, Madrid, 12 de julio de 1670, se copia el documento en Madrid, 5 de septiembre de 1674.

34 Ya en las aclaraciones que se hicieron de los capítulos matrimoniales de los marqueses de Quirra poco después de casarse aparece como testigo Alonso de Calatayud, junto a don Juan de Torres, criado de los marqueses del Fresno: AHNOB, FERNÁN NÚÑ̃E, C.,174, D. 30. En Arganda del rey, 29 de abril de 1660. En algunos documentos aparece como Alonso de Calatayud. 
relación que mantenían tanto él como su esposa con los marqueses era muy estrecha, tal y como, ha quedado reflejado en los testamentos de ambos ${ }^{35}$. Luisa de Velasco demuestra su confianza hacia él, al que alude de manera continuada para que ejecute sus últimas voluntades. Sin embargo, la marquesa no recurrió al conde del Real que estaba en Valencia y fue testigo también de sus últimas horas, según, él mismo relata a su otro hermano, Antonio (en el consejo de Aragón).

Las palabras elegidas por Alfonso de Calatayud cuando acepta ser su marmessor no son una simple fórmula protocolaria: veneración y obediencia. Lo mismo sucede cuando acepta el legado de su esposa señalando "el mucho amor y voluntad que ésta tenía a la dicha ilustre señora"36.

La marquesa comunicó sus legados jerárquicamente, empezando con su esposo, para continuar después con su madre, la condesa de Paredes, don Alfonso de Calatayud y doña Úrsula Ciurana, antes de citar a las que calificaba como "mis amigas" ${ }^{\prime 37}$. A Úrsula la distinguirá dejándole el aderezo de color violado engarzado en oro que, a su vez, la condesa de Fuensalida le había entregado para cuando contrajera matrimonio. Le dedica las siguientes palabras, las mismas que a su madre: "lo hago y entiendo hacer en señal del mucho amor y voluntad que la tengo..."

\section{El poder de la red femenina de Catalina de Velasco}

El testamento de Luisa de Velasco se redactó en complicadas circunstancias, cuando la muerte acechaba. La joven marquesa no designó a un heredero sino que concretó sus últimas voluntades a través de legados, acogiéndose a los fueros del reino de Valencia. Más allá de los niños de gloria, vestidos y alhajas asignados, quiso disponer, tal y como se le había concedido en sus capítulos matrimoniales, de cuatro mil ducados a repartir entre los criados y criadas de su casa, que todavía permanecieran a su servicio. A esta cuantía debían restarse las quinientas libras que había de-

35 AHNOB, Osuna, C. 603, D. 31. Último testamento del marqués de Quirra, Valencia, 27 de noviembre de 1674, ante el escribano Alejandro Ripoll. Alfonso de Calatayud era oidor de la Audiencia de Valencia: Molas Ribalta, Pere (1981): "Los colegiales mayores en la Audiencia de Valencia (siglos XVII-XVIII)". Pedralbes, vol. 1, Universitat de Barcelona, Barcelona, pp. 51-75, véase pp. $52,69$.

36 AHNOB, FRÍAS, C., 1414, D. 5. Testamento de doña Luisa de Velasco de 31 de julio de 1674.

37 Las ya citadas: las hijas de los condes de Paredes que se encontraban en Valencia, la condesa de Sinarcas y Anna, doña Guiomar Coloma y Castellví, y doña Inés $M^{a}$ Chavés y Mendoza.

38 AHNOB, FRÍAS, C., 1414, D. 5. Testamento de doña Luisa de Velasco de 31 de julio de 1674. 
jado para el sufragio de su alma, el gasto funerario y los legados en dinero especificados ${ }^{39}$.

Del mismo modo, la marquesa dejó establecido un tradicional orden de albaceas que respondía a la estructura jerárquica y familiar que la rodeaba. En él destacaba la prioridad otorgada al jefe de su Casa, el duque de Frías y, después, al marqués del Fresno (su hermano) por encima de su esposo, Joaquín Carroz. Tras éste destaca la preeminencia del duque de Gandía (don Pascual de Borja y Centelles) continuando, el conde del Real, el conde de Anna, don Alfonso de Calatayud y, por último, los doctores Miguel Sesé y Luis Bernardo -ambos curas parroquiales en la ciudad de Valencia, el primero de San Esteban y el segundo de San Lorenzo. La elección no era casual pero llama la atención, teniendo en cuenta, cómo se desarrollaron los acontecimientos con posterioridad.

Según se desprende de la correspondencia consultada, del listado que acabamos de citar pocos intervinieron realmente en las negociaciones posteriores. En un primer momento, el marqués de Quirra, como esposo de la fallecida, reclamó sus derechos sobre la herencia de doña Luisa ${ }^{40}$, pero su muerte ese mismo año hizo que el duque de Gandía interviniera pronto en el asunto. Éste ejerció como heredero del marqués, como todos en la familia habían previsto, durante aquella primera etapa -después la justicia le arrebataría todo el patrimonio de Nules y Quirra a favor de los Catalá de

39 Ibídem. Las disposiciones quedaron de la siguiente manera: a su esposo legó cien libras esperando y deseando que se conformara con eso, y dos niños que había en casa durante su vida, después debían pasar al convento nuevo de Carmelitas Descalzos fundado en la villa de Nules bajo la invocación de la Señora Santa Anna.

A su madre y a la condesa de Paredes sendos niños de pasión. A Alfonso de Calatayud el niño de gloria. A Úrsula Ciurana el aderezo ya señalado. A sus amigas (ya citadas) "algunas niñerías y dijes" cuyo reparto debía hacer Alfonso de Calatayud teniendo en cuenta lo que la marquesa le había comunicado en vida. A Antonia Fernández (mujer de Bautista Ximénez) lega cien libras moneda del reino de Valencia que le prometió con motivo de su boda y que debía pagar el día de San Juan de junio. A la que había sido su criada, María Viola, mujer de Gerónimo Rodríguez (cirujano) le deja un vestido de los mejores. Además, ordenó que la esclava María la Negra que estaba en su casa quedara libre y, además, le pide a su esposo que la trate "con mucha decencia y estimación" si decidiera ésta quedarse a su servicio.

40 El marqués de Quirra podía retener la dote mientras no se volviera a casar $y$, en este caso, todavía podría mantener la mitad mientras viviese. AHNOB, FRÍAS, C.,1414. D. 3: Carta de Don Carlos Valterra y Blanes del 23 de octubre de 1674, dirigida a la condesa de Paredes. Valterra, también era oidor y regente de la Real Audiencia (además de caballero de la orden de Montesa). 
Valeriola ${ }^{41}$. Aun así de la relación señalada habría que destacar el papel del Alfonso de Calatayud, el depositario real de los deseos de la marquesa y que participó activamente en el proceso que comandaron dos mujeres, excluidas aparentemente, pero que jugaron un papel fundamental en la resolución del asunto.

La muerte de Luisa de Velasco deja al descubierto las estrechas relaciones de las mujeres de la familia, su rol y capacidad de influencia y de obtener información. Las actuaciones de dos de ellas nos servirán para conocer el funcionamiento del entramado y su importancia, ya que fueron las encargadas de negociar y aclarar los pormenores de su herencia y, por tanto, la restitución de su dote. Por un lado, como es lógico su madre, la marquesa del Fresno (Catalina de Velasco y Tovar), y de la otra, la décima condesa de Paredes ( $M^{a}$ Inés Manrique de Lara), esposa de Vespasiano Gonzaga, virrey de Valencia en aquellas fechas (1668-1675) ${ }^{42}$.

La unión y reciprocidad familiar ha quedado reflejada en la correspondencia que la condesa de Paredes mantuvo con la marquesa viuda del Fresno en los meses posteriores a la muerte de Luisa de Velasco. La información que se extrae de estas misivas y, también, de otras que intercambiaron con otros sujetos, nos demuestra como la red femenina constituida desde palacio funcionaba al servicio de las respectivas Casas. Autorizadas para gestionar ciertos asuntos, como las dotes y sus restituciones, estas damas trataban todo tipo de temas ${ }^{43}$.

41 Los pleitos iniciados desde el principio darían después un resultado distinto a lo esperado por la mayoría de los coetáneos, al obtener los Catalá, primeramente, el marquesado de Nules y, más tarde, el de Quirra (agregado al anterior desde principios del siglo XVII). Haciendo valer su precedencia hereditaria del vínculo agnado (ficticio).

42 Catalina de Velasco y Ayala pertenecía a la casa de los condes de Fuensalida y era marquesa del Fresno por su matrimonio con el primer marqués, hermano a su vez del duque de Frías. Fallecido su esposo siguió utilizando el título a la vez que lo hacía su nuera Antonia de Luna y Portocarrero, como ya se ha señalado. $M^{a}$ Inés Manrique de Lara, condesa titular de Paredes, tras la muerte de su padre don Manuel Manrique de Lara y la renuncia de su madre doña Luisa Enríquez (1604-1660). Ésta abandonó su labor en palacio, dejó allí sus dos hijas y se retiró al convento de Malagón. Doña Luisa Enríquez con el hábito carmelita adoptó el nombre de Luisa Magdalena de Jesús hasta su muerte en 1660. Sobre esta última, véase: Pérez Villanueva, Joaquín (1986): Felipe IV y Luisa Enríquez Manrique de Lara, condesa de Paredes de Nava, un epistolario inédito. Ediciones de la Caja de Ahorros y Monte de Piedad de Salamanca, Salamanca, pp. 27-51.

43 AHNOB, FRÍAS, C., 414, D. 2. 
Así, por ejemplo, la condesa informaba a la marquesa del Fresno de las circunstancias a las que se enfrentaba el virrey en Valencia y sus actuaciones exitosas en el reino ${ }^{44}$. Igualmente, comentaban lo que acontecía con los distintos miembros de la familia. Preocupada por el bienestar de su hija primogénita, la virreina demostraba en sus cartas su intranquilidad por los peligros que acechaban a aquellas jóvenes damas en el Alcázar. Ambas interlocutoras conocían bien las intrigas, y los galanteos a los que se enfrentaban en su tierna juventud. Y aunque solía haber allegados pendientes de ellas, ya fuera en el interior de palacio o a través de las visitas de aquellas que vivían en la corte madrileña, el temor no disminuía. La condesa, ávida de noticias, dependía de los escritos que le remitía su propia hija, María Luisa Manrique, y, por supuesto, sus familiares, que podían visitarla, como la marquesa Catalina o la condesa viuda de Chinchón ${ }^{45}$.

La condesa de Paredes estaba pensando, igualmente, en sus dos hijas menores, que todavía permanecían bajo su cuidado en Valencia -en aquellas tierras del Turia, donde habían departido con Luisa de Velasco y con Mariana Ladrón, condesa de Sinarcas. Seguramente, porque era consciente, al escribir aquellas líneas, que pronto una de ellas ocuparía el puesto de su hermana, como así fue. Isabel Gonzaga se convirtió en dama (1675) coincidiendo precisamente con los esponsales de la futura condesa de Paredes y con el cambio de destino de Vespasiano Gonzaga ${ }^{46}$.

Otra parte de la red femenina de la familia aparece asimismo mencionada en la correspondencia. Es el caso de la hermana de la condesa, doña Isabel Manrique de Lara. Concretamente, la Paredes hacía referencia a uno de sus sobrinos ${ }^{47}$, y a la inquietud que su madre tenía por él. Estaba agradecida al conde de Monterrey, aunque supusiera no ver a su hijo,

$44 \mathrm{Ibídem}$. Real de Valencia, 23 de octubre de 1674. La condesa relata a la marquesa la buena noticia que habían logrado esa semana, de cómo el virrey había cogido a un bandido "el único que tenía algo turbada la quietud deste Reyno". Se rindió mal herido y para que se curara con mayor cuidado lo tenían en la torre del Real donde le guisaba su cocinero y le asistían dos criados de la confianza del conde además de los ministros de justicia.

45 Ibídem. Real de Valencia, 1 de enero de 1675. La condesa de Paredes a la marquesa del Fresno: Haciendo referencia a lo que ocurre en palacio decía: "[...] por esta razón como por otras muchas deseo ver a mi $\mathrm{M}^{a}$ Luysa fuera de aquella cassa".

46 La tercera, Josefa Gonzaga, contrajo matrimonio con Antonio Pimentel, marqués de Malpica.

47 Podría tratarse de Manuel Orozco, caballero de la orden de Santiago que murió en el ejército de Milán, ya que su hermano, el heredero de la Casa, Juan Antonio de Orozco y Manrique de Lara, fue mayordomo de Carlos II y murió en el Escorial a finales de siglo: Salazar y Castro, Luis, y Válgoma y Díaz-Varela, Dalmiro de la (1959): Historia Genealógica de la casa de Haro. Archivo Documental Español, tomo XV. Real Academia de la Historia, Madrid, pp. 96-97. 
pero, en aquellos días, lo que le preocupaba era el cambio en el gobierno de Flandes. Con la llegada del duque de Villahermosa, las esperanzas de la madre del muchacho se centraban en que el nuevo gobernador lo favoreciera del mismo modo ${ }^{48}$.

Las Sirvela también aparecen mencionadas con motivo de la muerte de una hermana de Ana María de Velasco, condesa de Siruela ${ }^{49}$. La Paredes recuerda lo amigas que eran Isabel y las hermanas Velasco -éstas habían coincidido en palacio ${ }^{50}$. Además, la marquesa del Fresno relata algunos de los episodios cortesanos-que después recoge la condesa de Paredes en sus misivas- que revelan la estrecha relación que mantenían la marquesa y Leonor de Velasco ${ }^{51}$.

El testamento de Luisa y la correspondencia de la condesa de Paredes con la marquesa del Fresno permiten sacar a luz un entramado de relaciones entre mujeres de la élite, una parte importante de ellas, servidoras palaciegas a lo largo del XVII. Dos sagas conectadas por la amistad forjada en la Corte y por el parentesco que las unía. En sus cartas la condesa podía tratar tanto temas familiares como las novedades que acontecían en el reino pero, sobre todo, aquella correspondencia tuvo por objeto la restitución de la dote y la herencia de doña Luisa de Velasco.

\subsection{Restitución de la dote y el papel de la virreina Paredes}

La condesa de Paredes se encargó desde el primer momento de mediar entre las partes y de favorecer los intereses de Catalina de Velasco y su

48 La condesa destaca que su sobrino ha heredado los méritos de su padre y confía en que le den un tercio si quedara alguno vacante: FRÍAS, C. 1414, D. 2. La condesa de Paredes a la marquesa del Fresno: Real de Valencia, 1 de enero de 1675, y 5 de febrero de 1675.

49 Podría estar haciendo referencia a doña María de Velasco de la Cueva Pacheco, monja de la Encarnación, ya que la otra hermana, Leonor de Velasco todavía está viva en esas fechas e incluso sucederá a su hermana.

50 AHNOB, FRÍAS, C.1414, D. 2. Real de Valencia, 23 de octubre de 1674.

51 AHNOB, FRÍAS, C. 1414, D. 2. La condesa de Paredes a la marquesa del Fresno: Real de Valencia, 1 de enero de 1675: La marquesa le había comentado como durante el cumpleaños de la reina había estado en compañía de Leonor, seguramente junto a la condesa viuda de Chinchón, en su posada; aunque esto había supuesto que se perdieran la comedia de don Agustín de Salazar, de quien también hablan. La marquesa destacó lo buena que era la obra y la condesa la faceta de poeta del autor quien en ese momento tenía la "habilidad" de escribir para Palacio. 
familia: comunicando la triste noticia y gestionando la recuperación de las joyas de la marquesa y del resto de la herencia. La virreina trabajó para cumplir con la obligación contraída con su parentela, a la que reconocía "obediencia". Y todo ello a pesar de las dificultades que suponía no sólo el negociar, primero, con el viudo y después, sobre todo, con el duque de Gandía, sino también, por lo complicado que era lidiar, además, con los fueros de aquel reino. Ella misma exponía a Catalina de Velasco su buena voluntad al respecto pero también la dificultad que tenía para ella entender en esa materia -por ser tan distintos al ordenamiento jurídico castellano ${ }^{52}$.

$Y$ todo parece indicar, si nos atenemos a la correspondencia consultada y a la resolución de los acontecimientos, que su labor fue fundamental. El oidor de la Real Audiencia, el doctor Isidoro Aparicio Gilart ${ }^{53}$ se lo reconoció a la excelentísima señora en una carta poco antes de que la Justicia Civil de Valencia mandara restituir la dote a los herederos de la marquesa de Quirra:

Yo he procurado vencer las deudas pero es cierto no me hubiera sido fácil conseguirlo si no hubiera mediado la autoridad de Vuestra Excelencia que lo ha allanado todo...54

Lo cierto es que la virreina estaba segura de su éxito desde principios de 1675, sobre todo, después de la muerte del marqués de Quirra, que era el que retenía la dote en un principio. Convencida, aseveraba en sus cartas a la marquesa del Fresno que sería ella la primera en recuperar el patrimonio antes que cualquier otro acreedor, antes incluso que el cuarto conde del Real:

52 Ibídem. Real de Valencia, 23 de octubre de 1674. La condesa de Paredes a la marquesa del Fresno.

53 Su fama de severo, rozando la crueldad marcó su etapa como juez criminal de la Audiencia. Estuvo casado pero terminó su vida como obispo: García Martínez, Sebastián (1991): Valencia bajo Carlos II, Villena, pp. 192-193. CANET APARISI, Teresa (1990): La magistratura valenciana (S. XVI-XVII), Universidad de Valencia, Valencia, p. 179: Oidor de las causas civiles de 1672 a 1684. PÉREZ GARCÍA, Pablo y CATALÁ SANZ, Jorge Antonio (1997): "Muerte y herencia de don Juan Tomás de Rocaberti" Estudis, núm. 23, pp. 211-259, véase p. 225.

54 AHNOB, Frías, C. 1414, D. 3. Valencia, 18 de abril de 1675. Isidoro Aparicio Gilart a la condesa de Paredes. AHNOB, FRÍAS, C. 404. D.8. Madrid, 19 de febrero de 1675. La marquesa viuda de Fresno le otorga poderes a la condesa de Paredes, doña María Inés Manrique, virreina de Valencia para gestionar la restitución dotal.

Para las transcripciones se ha mantenido la ortografía de la época, con la acentuación actual y separando palabras. 
[...] pues a más de la justificación creo que haviendo yo entrado en ello no faltará quien me haga el gusto de que en lo que necesitare gracia la tengáis, no ay sino encomendarlo a la Animas y creer que no perderé punto en serviros ${ }^{55}$.

A pesar de la participación del tercer conde del Real en el ajuste matrimonial de Luisa y las relaciones de amistad que ésta forió en Valencia con los Calatayud y el resto de la familia, tras su muerte la situación cambió, sobre todo, por la falta de descendencia de la pareja. A partir de ese momento, la lucha por la herencia, primero, de la marquesa y, después, del marqués marcó las relaciones de la parentela implicada. La reivindicación inicial de los bienes dotales por parte de la marquesa del Fresno (declarada heredera) concluyó con la lucha por los vínculos y títulos por parte del duque de Gandía ${ }^{56}$. Todo ello vino a complicar el cumplimiento de las últimas voluntades que Luisa señaló a través de legados, en aquel "peculiar" documento intestato, en el que no especificaba heredero - pero que fueron refrendadas en el testamento del marqués de Quirra. Éste expresó su voluntad de que fuera restituida la dote a su ilustre esposa, excepto las cuatro mil libras que la marquesa había dejado a sus criados que especificaba debían quedar a cargo de la herencia de él. Con respecto a la restitución dotal quería que se hiciera con los mismos bienes que ella había aportado al matrimonio ${ }^{57}$.

La marquesa Catalina de Velasco intentó evitar el enfrentamiento con su pariente el duque de Gandía $^{58}$ y, para ello, utilizó la mediación de la condesa de Paredes, e incluso escribió a la duquesa con el fin de que

55 AHNOB, FRÍAS, C., 1414, D. 2. Correspondencia entre la condesa de Paredes y la marquesa del Fresno (la mayor) con ocasión del fallecimiento de la marquesa de Quirra. Real de Valencia, 1 de enero de 1675.

56 Véase entre otros los trabajos del profesor Guia sobre la lucha por los títulos y el patrimonio del marqués después de su muerte: Guia Marín, Lluís (2011): "La guerra di successione spagnola e gli stati di Quirra e di Oliva in Sardegna". Quaderni Bolotanesi, Edizioni Passato e Presente, pp. 187-204.

57 AHNOB, Osuna, C. 603, D. 31. Último testamento del marqués de Quirra, Valencia, 27 de noviembre de 1674, ante el escribano Alejandro Ripoll.

58 Al tomar posesión de los bienes y herencia del marqués de Quirra, el duque de Gandía tuvo que asumir también sus deudas y el resto de temas pendientes como las restituciones dotales que todavía debía satisfacer el marqués. En este caso, nos centramos en las negociaciones con la familia de doña Luisa y los beneficiarios de sus legados, pero no eran los únicos. 
ésta influyera en su esposo. Mientras tanto, las criadas de la marquesa de Quirra, que habían quedado en Valencia, se quejaban amargamente del trato que recibían por parte de los nuevos titulares; hasta el punto de pasar serias dificultades ${ }^{59}$.

Las gestiones de la virreina estuvieron marcadas por su regreso a la Corte antes de haber finalizado el proceso y, por lo tanto, su labor. Esta era una de las cosas que le preocupaban, pues quería terminar con el asunto antes de partir de Valencia. Esto no lo consiguió enteramente, pero lo dejó lo suficientemente adelantado para controlarlo, junto a la marquesa, en la distancia, gracias a los contactos que mantenían, y que ejecutaban sus órdenes o peticiones. Todo se debió al cambio que se produjo en la cabeza del virreinato en abril 1675. Vespasiano Manrique Gonzaga cerraba por orden real su etapa en Valencia para trasladarse de nuevo a la Corte (como consejero de Indias) ${ }^{60}$. En una de sus cartas $M^{a}$ Inés Manrique de Lara agradecía la intervención de Catalina de Velasco y su clan en la consecución de la merced para su esposo ${ }^{61}$. La condesa no podía evitar congratularse porque fuera una concesión de la reina Mariana de Austria.

Este episodio demuestra la reciprocidad entre ambas familias. Y, además, la forma en la que se dirigía la virreina a su prima, y como hablaba del resto de implicados, confirma la relación de dependencia y subordinación de los Manrique de Lara con respecto a la marquesa y su Casa. Los condes debían tener ganas de regresar a la Corte, ella anhelaba reencontrarse con su hija, como relataba en sus cartas; para el virrey suponía rentabilizar su labor contra el bandidaje en el reino valenciano, ahora que la situación había empeorado ante las "crecientes protestas" en la ciudad, por sus últimas medidas $^{62}$. De igual forma, la notoriedad que alcanzaban los delincuentes valencianos podía perjudicarle. Ante esta situación no debe extrañarnos el interés que tenía la virreina en mostrar a "su prima" el buen hacer de su marido, y su abnegada dedicación al asunto de la marquesa de Quirra.

59 AHNOB, Frías, C. 404. D. 5. Valencia, 14 y 28 de mayo de 1675. Cartas entre doña Ana Álvarez y su hijastro, criado de la marquesa del Fresno.

60 Crespí de Valladaura Cardenal, Diego (2013): Nobleza y Corte en la regencia de Mariana de Austria (1665-1675), Tesis doctoral, Universidad Autónoma de Madrid, Madrid, p. 314.

A su regreso a la Corte también ejerció su cargo de gentilhombre de cámara de Carlos II y con posterioridad fue nombrado capitán general del Mar Océano: GARCÍA MARTíNEZ, Sebastián (1991), op. cit., pp. 189-194.

$61 A H N O B$, Frías, C1414, D. 2. La condesa de Paredes a la marquesa del Fresno: Real de Valencia, 5 de febrero de 1675.

62 GARCÍA MARTíNEZ, Sebastián (1991), op. cit., pp. 193-194. 
Es posible que la condesa ayudara a la familia antes de la muerte de Luisa de Velasco. Los marqueses de Quirra ya habían acudido a los tribunales, años antes, para asegurar la restitución dotal, un tema recurrente en la vida del marqués. En este caso es difícil concretar hasta qué punto pudieron incidir sus gestiones y las de su esposo sin evidencias documentales. Pero sí debemos de señalar que el conde de Paredes llevaba tres meses ejerciendo como virrey en Valencia cuando, en junio de 1668, se publicó una sentencia del tribunal de la Real Audiencia de Valencia a favor de los marqueses de Quirra y Nules "para seguridad y más fácil exacción de su dote y arras" 63 .

Pero no solo la condesa de Paredes respondió presta en la ayuda de la marquesa Catalina de Velasco, otras figuras destacadas hicieron también gestiones en el mismo sentido. Nos referimos, por un lado, a la princesa de Esquilache, la esposa del nuevo virrey de Valencia, el duque de Ciudad Real (Francisco Idiáquez Mújica y Brutón) y, por otro, a la marquesa de los Vélez, virreina en Cerdeña. Aunque no se ha podido comprobar hasta qué punto fueron decisivas sus actuaciones, lo que sí queda demostrado es que se ocuparon de cerrar algunos de los flecos dejados por la Paredes y de informar cortésmente ${ }^{64}$.

La nueva virreina de Valencia, doña Francisca de Borja y Aragón, debió de intervenir en el envío de la ropa y de las joyas de Luisa. La relación de todo aquello iba firmada por don Antonio Muñoz, mayordomo de la duquesa de Ciudad Real. En este punto, también, medió Gilart y uno de los criados de las señoras, Vicente Manuel y de Cerdán ${ }^{65}$.

63 El 12 de junio de 1668 se publicó una sentencia del tribunal de la Real Audiencia de Valencia $A H N O B$, Fernán Núñez. C. 174, D. 30. La causa de suplicación debía pasar al Consejo de Aragón, y siguiendo lo establecido en las pragmáticas y fueros del reino de Valencia la causa debía introducirse, acordarse y concluirse en el plazo de un año. Al no haber introducido la suplicación el procurador de don Antonio Joan de Centelles, los abogados de los marqueses suponían que no daría tiempo a finalizar el proceso. Esto les favorecía pero temían que el litigante optara por solicitar al Supremo Consejo de Aragón más tiempo para presentar y concluir la causa lo que había sucedido con anterioridad en otros casos. Por eso los marqueses al parecer comentaron la noticia de lo que ocurría a alguna persona en el Consejo para que supieran en este órgano que esta posible actuación sería contraria a los fueros.

64 AHNOB, Frías, C. 1414, D. 3. Cáller, 25 agosto de 1675: Antonio de Aguiar a la marquesa del Fresno. Frías, C. 404. D. 5. Valencia, 23 abril 1675.

$65 A H N O B$, Frías, C1414, D. 2. Memoria de la ropa de la señora marquesa del Fresno y memoria del estado en el que se encontraron los aderezos (sin fechar). D. 3. Valencia, 18 de abril de 1675: Isidoro Aparicio Gilart a la condesa de Paredes. Aunque la condesa tenía mucho interés en llevar las joyas, personalmente, parece que, finalmente, no pudo al regresar en abril a la Corte. Valencia, 8 de octubre de 1675: carta de Vicente Manuel y de Cerdán a 
Catalina de Velasco se valió, de igual modo, de sus contactos en Cerdeña $y$, aprovechando la estancia del sexto marqués de los Vélez (don Fernando Joaquín Fajardo) en el virreinato, mantuvo correspondencia con su primera esposa, $M^{a}$ Juana de Aragón Folch de Cardona. Uno de los temas que preocupaba a los Fernández de Velasco era los beneficios que les correspondían del trigo que se extraía en la isla y de los derechos del puerto de Ollastra ${ }^{66}$.

La otra figura clave de la negociación y gestión fue Alfonso de Calatayud depositario de la última voluntad de la difunta. A él cita reiteradamente como conocedor de los criterios que se debían seguir en el reparto de niñerías, dijes, legados y, por supuesto, la cuantía económica (los cuatro mil ducados con los descuentos $)^{67}$. Además, cabe destacar que era oidor de la Audiencia de Valencia, éste es un aspecto interesante para el análisis, ya que no fue el único miembro de la institución que participó en la resolución de la herencia de la marquesa-nos referimos a Gilart y a Valterra ${ }^{68}$.

Alfonso de Calatayud quedó encargado de las mandas de la marquesa, lo que le obligó a participar en las gestiones entre los Fresno y el resto de implicados. El fiel servidor de los marqueses, el mayordomo Juan de Torres, actuó como su interlocutor ${ }^{69}$.

Las gestiones de todos ellos nos demuestran hasta qué punto era importante disponer de miembros de la familia, aliados y clientela en las distintas esferas de poder de la monarquía simultáneamente.

Catalina de Velasco. En ella el criado hace referencia a la cama rica de la marquesa y los problemas para intentar venderla, sobre todo, la colgadura, ya que por el maderaje daban setenta libras.

66 AHNOB, Frías, C. 1414, D. 3. Cáller, 6 de julio de 1675, Don Juan Bautista Carnicer a la marquesa del Fresno.

67 AHNOB, Frías, C. 1414, D. 5. Testamento de doña Luisa de Velasco.

68 AHNOB, Frías, C. 1414. D. 3. Carta de Don Carlos Valterra y Blanes del 23 de octubre de 1674, dirigida a la condesa de Paredes. Valencia, 18 de abril de 1675: Isidoro Aparicio Gilart a la condesa de Paredes. AHNOB, Frías, C. 1414, D. 5. Testamento de doña Luisa de Velasco.

69 AHNOB, Frías, C. 1414, D. 5, Valencia, 9 de agosto de 1678, Valencia, 13 de septiembre de 1678: Pedro Domingo Malfey, criado de don Alfonso de Calatayud, gestiona con don Juan de Torres el envío de documentación, como la cláusula que le da facultad para la repartición entre las criadas y criados de los cuatro mil ducados, a través de la casa del señor Antonio de Calatayud, residente en la villa y corte de Madrid. 


\subsection{Criados de sus señoras. La red subordinada}

Catalina de Velasco y la condesa de Paredes hicieron funcionar el engranaje clientelar $y$, por tanto, dependiente de ambas familias para conseguir sus objetivos. Una red subordinada pero vital, de favores, peticiones y correspondencias.

La estrecha relación de los Fernández de Velasco con la compañía de Jesús propició que el jesuita, Antonio de Aguiar, se convirtiera en una de las piezas utilizadas, en este caso, para mantener informada a la marquesa del Fresno desde Cagliari. Al servicio del virrey de Cerdeña, el marqués de los Vélez, hizo de intermediario entre la señora y el regidor don Juan Bautista Carnicer (procurador y administrador de los estados del marqués de Quirra en Cerdeña). Y, también, a través de la marquesa de los Vélez, como ya se ha comentado, remitió información sobre el asunto. Su correspondencia en este sentido termina en el verano de 1675 , con el desplazamiento en septiembre del marqués a Nápoles, para ocupar su virreinato. Aguiar no desaprovechará la oportunidad para desearle "los mayores puestos" al hijo de Catalina, don Pedro Fernández de Velasco, marqués del Fresno -que en aquellas fechas cumplía un año de su regreso a la Corte tras su estancia como embajador extraordinario en Londres. Como criado de su Casa y deudor suyo se mostraba dispuesto a cumplir fielmente sus peticiones: "como a su [menor] criado no deje de mandarme, pues en todas partes reconoceré lo que debo a la Casa de vuestra señoría"70.

Entre los criados de la marquesa de Quirra destacaremos aquí los que, además, intervinieron de alguna manera en las gestiones sobre su herencia, sirviendo también como fieles servidores de sus señoras: Catalina de Velasco y $M^{a}$ Inés Manrique de Lara, principalmente. Uno de ellos fue Vicente Manuel y de Cerdán, y su mujer María ${ }^{71}$. Ambos mantenían correspondencia con la marquesa viuda del Fresno, aunque sólo se ha podido consultar las cartas de él. Agraciados en el reparto de la herencia también aguardaban el momento de obtener lo que les correspondía como el resto de criados. Incluso podemos interpretar malestar ante la situación, cansados de esperar. Aun así el que se califica como el más humilde de los criados no dejó de mostrar su obediencia y subordinación:

70 AHNOB, Frías, C. 1414, D. 3, Cáller, 25 agosto de 1675. Antonio de Aguiar a la marquesa del Fresno.

71 Tras analizar la documentación, creemos que se trata de María Escobedo una de las criadas más apreciadas por la marquesa de Quirra, aunque no podernos asegúralo completamente. 
[...] estos son sentires que para eso hay tantos pleitos, yo es cierto que a VS no he de poner ninguno por doscientas y [treinta] libras que me tocan a mí y a mi mujer y así si VS tuviere gusto de darlas me hará mucha merced y sino tan criados quedaremos de VS de una manera como otra $[\ldots]^{72}$.

Incluso en alguna carta le solicita a la marquesa novedades sobre la monarquía ${ }^{73}$. Este criado, fiel servidor también de la condesa de Paredes, aprovechó igualmente sus misivas para reconocer la labor de ésta ante la marquesa:

[...] lo que la puedo asegurar a VS que lo que a VS han dado, se lo debe a mi señora la condesa de Paredes malo o bueno que fuera un pleito que VS no le viera acabado ${ }^{74}$.

En otra de sus cartas vuelve a defender a la condesa en este caso por las palabras vertidas por la condesa del Real. Vicente Manuel le explica lo agradecida que debe estar a la Paredes porque no se obligó "en nombre de vuestra señoría a satisfacer las deudas y legados de mi señora". En su opinión, ella no tenía porque atribuir la mayor parte de los legados así que los legatarios tenían derecho a quejarse, pues habían perdido la oportunidad de pedirlo al duque (octubre de 1675) ${ }^{75}$.

Entre las criadas sobresale Ana Álvarez de Camargo. Las misivas que remitía a su hijastro y las referencias que otros hacían de ella nos han servido para valorar su importancia, conocer su nivel de relación con sus señoras y extraer información relevante -sobre los avances del proceso real de cumplimiento de las últimas voluntades de la marquesa de Quirra.

72 AHNOB, Frías, C. 1414, D. 3. Carta de Vicente Manuel y de Cerdán a Catalina de Velasco. Valencia, 8 de octubre de 1675. La familia de Vicente Manuel y de Cerdán estaba también presente en la casa de la marquesa del Fresno, pues una de sus hijas, María Teresa se encontraba como criada de las señoras en la Corte.

73 Ibídem. Valencia, 19 de noviembre de 1675.

74 Ibídem. Valencia, 8 de octubre de 1675.

75 Ibídem. Valencia, 29 de octubre de 1675. 
Doña Luisa de Torres y doña Ana Álvarez fueron dos de las criadas más favorecidas, junto a María Escobedo, en el testamento de la marquesa Luisa de Velas $\mathrm{Co}^{76}$. Pero no fue fácil cumplir con sus últimas disposiciones. Con respecto a sus criados y criadas fue clara en sus indicaciones a Alfonso de Calatayud. Tras hacerse cargo de su alma y sus deudas, el resto debía ser para su "familia" especificando una mejora para Luisa de Torres, a la que dejó doscientos ducados. Para cumplir con lo establecido, en un primer momento, la marquesa del Fresno y el duque de Gandía llegaron a un acuerdo, gracias a la condesa de Paredes. Aunque este pacto tuvo sus complicaciones en la práctica, según aparece reflejado en la correspondencia de don Alfonso de Calatayud, don Juan de Torres y doña Ana Álvarez. Hasta el punto de no quedar claro a quién correspondía el pago de algunos de los legados ${ }^{77}$.

Luisa de Torres había perdido la visión a su servicio y no se encontraba con ella en Valencia, residía en Madrid. La marquesa especificó que su legado fuera directamente a la joven y no a sus padres. En este punto, aunque sin poder confirmarlo, podemos suponer que Luisa era familia de don Juan de Torres, al servicio de los marqueses del Fresno. Además, podría ser que éste fuera el hijastro de Ana Álvarez de Camargo ${ }^{78}$.

Cuando doña Luisa de Velasco inició su nueva etapa de casada, lo hizo acompañada de algunas criadas que habían estado ligadas a su casa familiar. Es el caso de Ana Álvarez. Todo parece indicar que había pasado la mayor parte de su vida al servicio de los Fernández de Velasco, pero el matrimonio de la pequeña de la familia la apartó de su "hogar". Escoltó a Luisa hasta Valencia y allí permaneció más allá de la muerte de su señora, pero poco tiempo después también ella falleción ${ }^{9}$. Hasta ese último instante, Ana Álvarez aguardó el pago de los legados junto a otras criadas ${ }^{80}$,

$76 A H N O B$, Frías, C. 1414, D. 5. Los vestidos y ropas de su servicio, excepto los ya legados, debían distribuirse y repartirse entre las criadas que en ese momento estaban trabajando en su casa. La distribución recayó en doña Ana Álvarez, la primera en poder elegir un vestido para ella (e igualmente la parte de ropa) y de igual modo María Escobedo estaría mejorada con otro. El resto se repartiría entre todas las criadas.

77 AHNOB, Frías, C1414, D. 5. Valencia, 9 de agosto de 1678: Don Alfonso de Calatayud a don Juan de Torres. Don Alfonso decía desconocer a quién correspondía el pago pendiente a Luisa de Torres, ya que entraba en el acuerdo alcanzado por la Paredes, igual que en el caso de doña Ana Álvarez (ya fallecida). Al parecer los criados del marqués de Quirra habían recibido lo que les correspondía por parte del duque de Gandía.

78 AHNOB, Frías, C1414, D. 5.

79 AHNOB, Frías, C. 1414, D. 5. Testamento de doña Luisa de Velasco de 31 de julio de 1674. 
comunicando puntualmente el proceder de los duques de Gandía, que en un primer momento, se hicieron con el control de la herencia del marqués de Quirra. Cuando en abril de 1675 la condesa de Paredes partió hacia la Corte, doña Ana se convirtió en la informadora de la familia y gestionó lo que se le ordenaba en comunicación con los otros agentes de la marquesa -por ejemplo, con Vicente Manuel de Cerdán. No sólo mantenía correspondencia con su hijo, también lo hacía con la propia Catalina de Velasco. En esas cartas se puede apreciar la familiaridad, respeto y obediencia con la que doña Ana se dirigía a las mujeres de la Casa: la señora (la marquesa madre), doña Juana (la condesa de Chinchón), y a las que consideraba también "sus señoras", la condesa de Paredes y sus hijas. Además, en ellas, hacía constantes referencias a doña Luisa Torres y a otras criadas ${ }^{81}$.

Ana Álvarez siempre dispuesta a servir a sus señoras obedeció cada una de las instrucciones que le llegaban de Madrid, como cuando recibió el encargo de servir a una de las criadas de la nueva virreina. Siguiendo las indicaciones de doña Juana (condesa de Chinchón) se puso en contacto con la criada de la princesa de Esquilache, doña Antonia de Chaves, para verla y servirla en lo que le mandare ${ }^{82}$.

Su obediencia y respeto fue tal, que a pesar de desprenderse en sus cartas cierta desesperación y descontento, al sentirse abandonadas, continuaron cumpliendo con las órdenes que llegaban de sus señoras desde la Corte. Doña Ana no osó importunar a su señora la marquesa madre y prefirió resignarse a los designios divinos y criticar a los duques de Gandía, aunque sabía que tras la restitución dotal el pago de los legados por parte de la que se había erigido en heredera hubiera solucionado la situación de inmediato. Remediando sus "miserias", lo que les hubiera permitido, quizá,

C. 404, D. 5 . Aunque no lo puedo asegurar, por lo que se puede deducir en la documentación, la Ana Álvarez que aparece citada en el testamento y en alguna de las cartas de Alfonso de Calatayud es la misma mujer que escribe cartas después de la muerte de la marquesa desde Valencia a su hijo en la corte y al servicio de la familia Fernández de Velasco, que podría ser don Juan de Torres, que al organizar la correspondencia especifica que se trata de su "Madrastra Anna Álvarez de Camargo".

AHNOB, Frías, C.1414. D. 5. Valencia, 9 de agosto de 1676: Carta de Alfonso de Calatayud a Juan de Torres.

$80 A H N O B$, Frías, C1414, D. 5. En sus cartas cita constantemente a Ana y Antonia, podrían ser incluso sus hijas.

81 Además, le mandó un ungüento para Luisa de Torres y les explicaba a sus familiares que esto no podía perjudicarla.

82 AHNOB, Frías, C. 404. D. 5, Valencia a 23 de abril de 1675. 
regresar a Madrid. En el caso de doña Ana, la muerte terminó con su sufrimiento. Podemos suponer que las señoras de la Casa intentaron evitar, por todos los medios, asumir los pagos y las deudas contraídas por el marqués. No en vano eran las deudas del marqués de Quirra las que habían provocado el empeño de las joyas de la marquesa, en definitiva, de la familia ${ }^{83}$. $Y$ es que para hacerse con la herencia y ejecutar los legados del mismo modo había que asumir las deudas, y en este capítulo, los Fernández de Velasco se resistieron. Además, los herederos de la marquesa de Quirra tenían a su favor la disposición final del marqués en su testamento. En esta línea, se entiende la utilización de sus propios criados, no sólo como fuente de información, sino también como instrumentos de presión ante los duques. Éstos, por su parte, asediados por los pleitos y ante el riesgo de perder la herencia del marqués prefirieron evitar a los acreedores.

La Justicia Civil de Valencia vino a darle la razón a la marquesa viuda del Fresno al mandar restituir la dote. $Y$ ese éxito quedó reflejado en la correspondencia de la condesa de Paredes y de sus "criados", pero la liquidación de los legados tuvo que esperar más tiempo ${ }^{84}$. También en el caso de las joyas. Todavía en marzo de 1676, la marquesa del Fresno y el duque de Gandía intercambiaban pareceres sobre el asunto. El noble valenciano esperaba que su "tía" se hubiera dado ya por satisfecha en este punto. Pero no era así, a pesar de los esfuerzos de la red femenina y del logro alcanzado con la devolución de la dote, perduraban flecos por cerrar ${ }^{85}$. Por ejemplo, el pago que Antonio Maynon "arrendador de los estados" del marqués en Cerdeña debía a la marquesa y que tanto Catalina de Velasco como el duque de Gandía reclamaban ${ }^{86}$.

$83 A H N O B$, Frías, C. 1414, D. 3. Valencia, 17 de septiembre de 1675, en esta carta a la marquesa del Fresno se explica que la cruz de diamantes de Montesa se empeñó en varias ocasiones, una de ellas la marquesa de Quirra lo hizo para pagar los alimentos de su casa con ocasión del embargo que se había hecho en las rentas de Nules por el tema de Gaspar Basset (el pretendido hijo del marqués de Quirra).

84 La declaración no ha podido ser consultada por el mal estado de conservación del documento (AHNOB, Fernán Núñez, C. 243, D. 16) pero a través de la correspondencia referida sí se ha podido confirmar este dato.

$85 A H N O B$, Frías, C. 1414, D. 3, Gandía, 30 de marzo de 1676. El duque de Gandía a su señora y tía la marquesa del Fresno.

86 Ibídem. Valencia, 27 de agosto de 1675. Antonio Maynon fue uno de los individuos más citados en la correspondencia de Vicente Manuel. 
Los legados de Luisa de Velasco resultaron difíciles de cumplir por las deudas contraídas. La propia marquesa del Fresno, heredera de su hija tuvo que establecer en su testamento varías cláusulas para cumplir con los acreedores y con las criadas de su hija (1683). Como su heredera tuvo que hacer frente a las reclamaciones de los acreedores de los marqueses de Quirra. Según Vicente Manuel, acudían a ella porque no conseguían nada del duque de Gandía. Por eso le recomendaba (en 1675) que lo dilatase en el tiempo y así lo hizo hasta el momento de su muerte ${ }^{87}$.

\section{Conclusiones}

La marquesa del Fresno, Catalina de Velasco, hizo valer su relación familiar, como pariente mayor $y$, seguramente, la preeminencia de su Casa en la Corte para gestionar en su favor la herencia, restitución de la dote y las últimas voluntades de su hija, Luisa de Velasco. El entramado femenino fue el primero en actuar. Estas mujeres, acostumbradas a medrar en la Corte incluso dentro del propio Alcázar, aplicaron lo aprendido en beneficio de su linaje.

La familia de Luisa de Velasco demostraba tener una disposición adecuada y privilegiada de su parentela en diferentes espacios de poder. Tanto por el que atesoraban en la Corte, y que servía de moneda de cambio, como por las conexiones puntuales que tenían en otros rincones de la monarquía, en este caso, en el virreinato de Valencia, donde se situaba la condesa de Paredes. Todo lo cual ayudó a la Casa a recuperar el patrimonio invertido en este matrimonio. El papel de la condesa parece que fue decisivo para obtener la restitución de la dote y aumento de doña Luisa, sobre todo, porque hizo valer su estatus en Valencia tocando las teclas adecuadas en la Audiencia y con la ayuda de los criados de ambas.

Podemos observar, atendiendo a las palabras de la virreina, la relación de dependencia que tenía la propia condesa y su esposo, Vespasiano Gonzaga, con Catalina de Velasco y su familia, a los que reconocía deber parte de su ascenso. Del mismo modo, la trágica muerte de Luisa nos permi-

87 AHNOB, Frías, C. 1414, D. 5. Testamento de Catalina de Velasco, y clausula aclaratoria: Madrid, 25 de abril de 1683. En el declara que fue heredera de la marquesa de Quirra y manda se dé satisfacción a sus acreedores hasta en lo que alcanzara dicha herencia. Manda a su heredero también se ajuste la dependencia las criadas de la marquesa de Quirra.

$A H N O B$, Frías, C1414, D. 3. Valencia, 27 agosto 1675, Vicente Manuel y de Cerdán a doña Catalina de Velasco el 8 de octubre de 1675: Las joyas de la marquesa de Quirra habían sido empeñadas en varias ocasiones para pagos, por ejemplo, para la dote de Antonia Fernández. 
te comprobar cómo funcionaba la reciprocidad entre ambos núcleos parentales. Para los Fernández de Velasco fue un alivio contar con el apoyo y las gestiones de la condesa para resolver, en la distancia, aquel delicado asunto.

Los "favores" realizados los unos a los otros, servían para retroalimentar las relaciones de dependencia y correspondencia mutua que mantenían las casas nobiliarias, unidas por enlaces a veces ya lejanos o relaciones fuera del linaje. Como se puede observar en la relación que mantienen los Manrique de Lara con los Fernández de Velasco, representado en esta ocasión por la viuda del marqués del Fresno y por la titular del condado de Paredes, todos los miembros de la red familiar salen beneficiados. La merced podía recaer individualmente en alguno de sus miembros, de manera inmediata, pero a corto, medio o largo plazo, consecuentemente, influía en el conjunto del entramado, tanto familiar como clientelar. Esto consolidaba e incluso podía incrementar la red de relaciones en la que participan de manera tanto activa como pasiva.

Pero sin duda lo que más destaca era la relación de correspondencia mutua que existía entre ambas y el resto de damas. Tenían en común sus lazos familiares y habitar en palacio o haberlo hecho. Son pocas las cartas y sólo contamos con las misivas de una de ellas, aun así, se ha podido extraer información valiosa para hacer una primera aproximación a lo que podría ser la red que éstas conformaban y esbozar una hipótesis sobre el puesto que ocupaban cada una de ellas. Además de la relación de parentesco que mantenían entre ellas, había una experiencia común que compartían por sus vivencias en la Corte. Conocían a la perfección los entresijos cortesanos y seguían cuidando la red, creada y perpetuada en palacio.

En concreto, rescatamos la figura de Luisa de Velasco, una pieza menor en el entramado de los Fernández de Velasco. Su matrimonio con el marqués de Quirra y la gestión de su herencia sirvieron para reforzar la cohesión de la red de alianzas y la madeja de relaciones de dependencia de la familia, gracias a la estrecha relación que ésta mantuvo con una de las mujeres de la red parental, la condesa de Paredes.

Las alianzas matrimoniales consolidaban y ampliaban la red en tanto en cuanto los miembros que la conformaban estuvieran vivos o generaran descendencia. En este caso, el que la unión no diera frutos quebró la tela de araña en esta zona de influencia. Pero lo que sí podemos apreciar es como la reciprocidad funcionaba entre el resto de piezas. Alianzas familiares de amistad y dependencia se ponían a funcionar incluyendo el nivel clientelar de cada una de estas familias, a veces con clientes compartidos. Se activaba la red con el fin de obtener el beneficio del que lo necesitase en ese momento, aunque la puesta en marcha del engranaje pudiera provocar 
disfunciones.

La identificación de sus miembros nos ha permitido conocer cómo esta red, que se generaba en el epicentro de la monarquía, conectaba otros espacios de poder y áreas regionales. El análisis de su funcionamiento nos permite a su vez comprender el rol que jugaban y las propias dinámicas del grupo.

\section{Bibliografía}

Callado Estela, Emilio (2004): "Cameros versus Manrique de Lara. Historia de un desencuentro entre el Arzobispo y el Virrey de Valencia en el marco de las tensiones jurisdiccionales Iglesia-Corona (1669)". Aranda PÉrez, Francisco José (Coord.): La declinación de la monarquía hispánica. VII Reunión Científica de la Fundación Española de Historia Moderna. Universidad de Castilla La Mancha, Cuenca, pp. 661-676.

CANET APARISI, Teresa (1990): La magistratura valenciana (S. XVI-XVII), Universidad de Valencia, Valencia.

CATAlÁ Sanz, Jorge Antonio (1995): Rentas y patrimonios de la nobleza valenciana en el siglo XVIII. Siglo Veintiuno, Madrid.

Chiquillo PÉrez, Juan A. (1991): "La nobleza austracista en la guerra de Sucesión. Algunas hipótesis sobre su participación". Estudis: Revista de historia moderna, $\mathrm{n}^{\circ} 17$, pp. 15-148.

Crespí de Valladaura Cardenal, Diego (2013): Nobleza y Corte en la regencia de Mariana de Austria (1665-1675), Tesis doctoral, Universidad Autónoma de Madrid, Madrid.

FELIPO ORTS, Amparo (2007): “El testament del marqués de Villatorcas i la disputa del comte de Cervelló per l'heréncia paterna. Una altra conseqüencia de l'exili austracista". Aguaits, 24-25, pp. 97-121.

FernáNDEZ NadAl, Carmen María (2011): "Damas, poder y diplomacia en el siglo XVII: Antonia de Luna, Luisa de Ayala y María Teresa Ronquillo". Dossiers Feministes, 15, pp. 101-126.

García Martínez, Sebastián (1991): Valencia bajo Carlos II. Ayuntamiento de Villena, Villena.

GuIA Marín, Lluís (2011): "La guerra di successione spagnola e gli stati di Quirra e di Oliva in Sardegna". Quaderni Bolotanesi, Edizioni Passato e Presente, pp. 187-204.

Imízcoz Beunza, José M. (2006): "Las redes sociales de las élites, conceptos, fuentes y aplicaciones". Soria Mesa, Enrique, Bravo Caro, Juan Jesús y Delgado BARRAdo, Miguel (Coord.): Las élites en la época moderna: La monarquía española, vol. 1, Universidad de Córdoba, Córdoba, pp. 77-112. 
KalneIN, Albrecht Graf von (2001): Juan José de Austria en la España de Carlos II. Lleida, Milenio.

López-CoRdón CORTEZO, M. Victoria (2009): "Las mujeres en la vida de Carlos II". Ribot García, Luis A. (coord.): Carlos II: el rey y su entorno cortesano. Centro de Estudios Europa Hispánica, Madrid. pp. 109-140.

- (2003): "Entre damas anda el juego: las camareras mayores de Palacio en la edad moderna". Cuadernos de Historia Moderna. Anejos, №. 2, pp. 123-152.

MAREK, Pavel (2011): "Luisa de las Llagas. La abadesa de las Descalzas y el proceso de la comunicación política y cultural entre la corte real española y la imperial", Pedralbes, 31, pp, 47-90.

- (2009): "Las damas de la emperatriz María y su papel en el sistema clientelar de los reyes españoles. El caso de María Manrique de Lara y sus hijas" Martínez Millán, José y Marçal Lourenço, Maria (coord.): Las relaciones discretas entre las Monarquías Hispana y Portuguesa: Las Casas de las Reinas (siglos XV-XIX), 3 vols., vol. 2, Polifemo, Madrid, pp. 1003-1036.

Martínez Millán, José (1989): "Élites de poder en tiempos de Felipe II (15391572)". Hispania: Revista española de historia, núm. 171, pp. 111-149.

MATEU IBARS, Josefina (1963): Los virreyes de Valencia. Ayuntamiento de Valencia, Valencia.

Maura Gamazo, Gabriel (1911): Carlos II y su Corte, Ensayo de reconstrucción biográfica, Tomo I, Madrid.

Molas Ribalta, Pere (1981): "Los colegiales mayores en la Audiencia de Valencia (siglos XVII-XVIII)". Pedralbes, vol. 1, Universitat de Barcelona, pp. 51 . 75.

Novo Zaballos, José Rufino (2008): "La Casa real durante la regencia de una reina: Mariana de Austria". Martínez Millán, José y MarÇal Lourenço, Maria (coord.): Las relaciones discretas entre las Monarquías Hispana y Portuguesa: Las Casas de las Reinas (siglos XV-XIX). 3 vols. Vol. 2, Polifemo, Madrid, pp. 483-547.

Oliván SANTAliestra, Laura (2008): "La dama, el aya y la camarera: Perfiles políticos de tres mujeres de la Casa de Mariana de Austria" Martínez MLLLÁN, José y MARÇAL LoURENÇO, Maria (coord.): Las relaciones discretas entre las Monarquías Hispana y Portuguesa: Las Casas de las Reinas (siglos XV-XIX), 3 vols., vol. 2, Polifemo, Madrid, pp. 1301-1356.

Pérez García, Pablo y CatalÁ Sanz, Jorge Antonio (1997): "Muerte y herencia de don Juan Tomás de Rocaberti". Estudis, núm. 23, pp. 211-259. 
Pérez VillanueVa, Joaquín (1986): Felipe IV y Luisa Enríquez Manrique de Lara, condesa de Paredes de Nava, un epistolario inédito. Ediciones de la Caja de Ahorros y Monte de Piedad de Salamanca, Salamanca.

Salazar y Castro, luis, Válgoma y Díaz-Varela, Dalmiro de la (1959): Historia Genealógica de la Casa de Haro. Archivo Documental Español, tomo xV. Real Academia de la Historia, Madrid.

VIlar y Pascual, Luis (1860): Diccionario Histórico Genealógico y heráldico de las familias Ilustres de la monarquía española, tomo III, Imprenta de D. F. Sánchez. Madrid. 
Figura 1. Árbol genealógico de la familia de los condes del Real

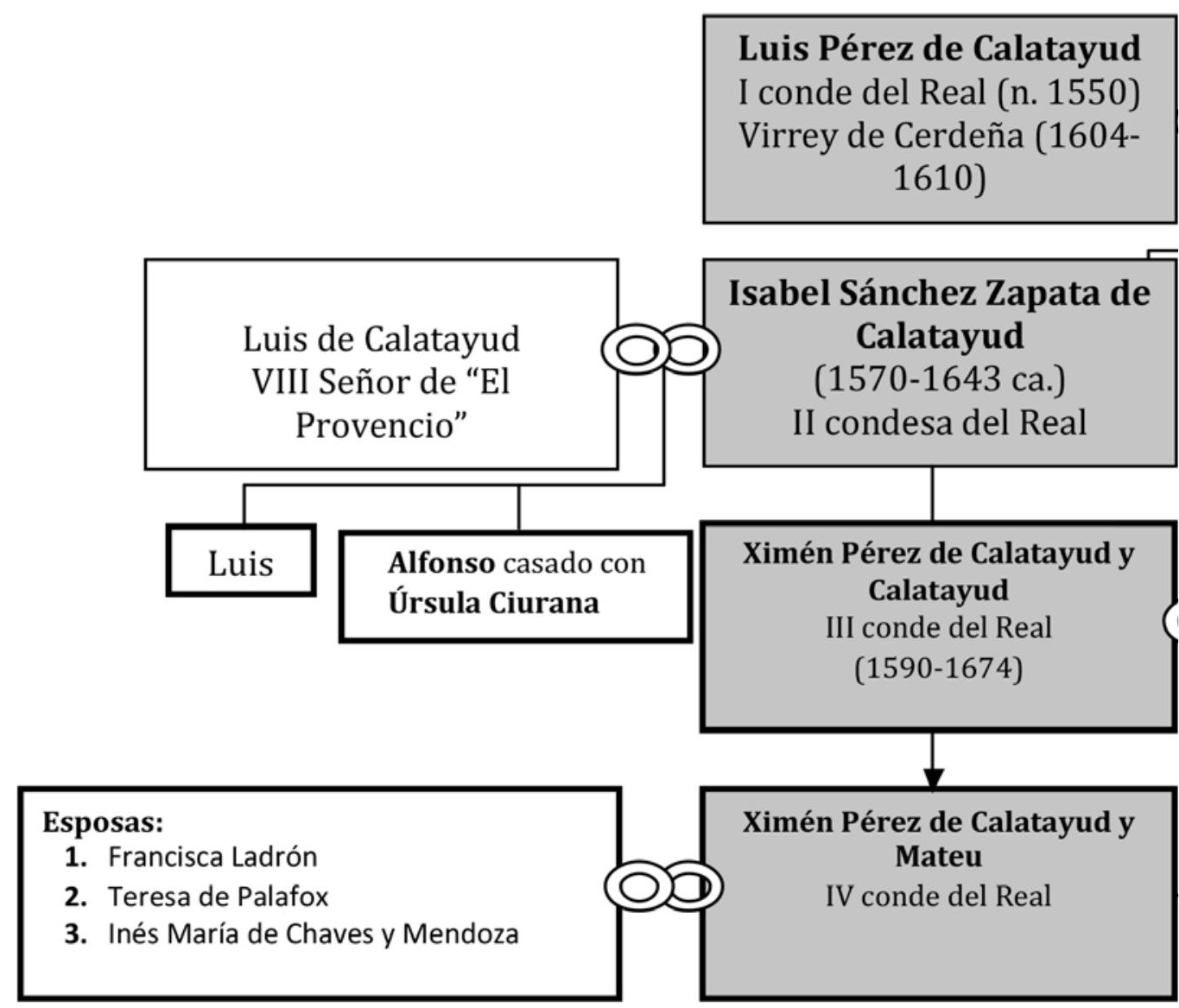

Fuente: Elaboración propia gracias a la documentación consultada entre la que destaca: $A H N O B$, Leg. 1052-1. OSUNA, GN. 7, D. 18. 


\section{Marina Bou (1555-1644)}

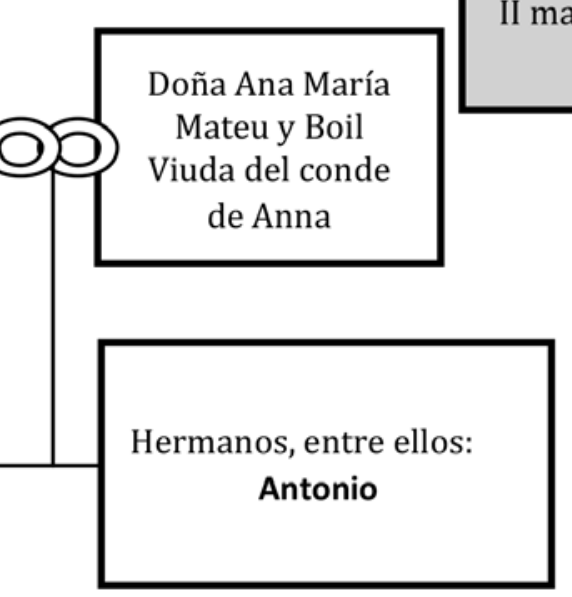

Joaquín Carroz de Centelles

II marqués de Quirra y Nules

(1615-1674)

\section{Cristóbal de Centelles}

Viudo de Alemanda Carroz

marquesa de Quirra
PRIMERA ESPOSA

boña Estefanía de Moncada

Hija del III marqués de Aytona

(1614-1638 ca.)

SEGUNDA ESPOSA

Doña Beatriz de Saavedra

Hija del V conde de Castellar

(m. 1659)

TERCERA ESPOSA

Doña Luisa de Velasco

Hija del I marqués del Fresno

(1636 ca.-1674) 
Figura 2. Red de mujeres en torno a Luisa de Velasco.

\begin{tabular}{|c|c|c|c|c|c|c|c|c|}
\hline & & & & & & & & $\begin{array}{c}\text { Da Mariana Enríquez }^{\text {a }} \\
\text { Viuda de Pedro de Velasco y } \\
\text { Rojas } \\
\text { Tutora de Catalina de Velasco } \\
\text { y sus hermanos } \\
\text { Bisabuela } \\
\text { Dama de honor }\end{array}$ \\
\hline & & \multicolumn{4}{|c|}{$\begin{array}{c}\text { Da Luisa Enríquez } \\
(1604-1660) \\
\text { Señora de Luján } \\
\text { Dama de la reina Isabel, dama mayor y aya de la } \\
\text { Infanta Maria Teresa }\end{array}$} & \multirow{2}{*}{\multicolumn{2}{|c|}{$\begin{array}{l}\text { Antonia de } \\
\text { Luna } \\
\text { Marquesa del } \\
\text { Freno } \\
\text { Condesa de } \\
\text { Peñaranda } \\
\text { Cuñada } \\
\text { Dama }\end{array}$}} & $\begin{array}{c}\text { Da Jerónima de Ayala } \\
\text { Abuela }\end{array}$ \\
\hline \multirow[t]{3}{*}{$\begin{array}{l}\text { Da Leonor } \\
\text { de Velasco } \\
\mathrm{XI} \text { condesa } \\
\text { de Siruela } \\
\text { Dama }\end{array}$} & $\begin{array}{c}\mathbf{D}^{\mathbf{a}} \text { Ana } \mathbf{M}^{\mathbf{a}} \\
\text { X condesa de } \\
\text { Siruela } \\
\text { Casada con } \\
\text { Bernardino } \\
\text { Velasco y } \\
\text { Ayala } \\
\text { VII conde de } \\
\text { Fuensalida } \\
\text { Tia politica } \\
\text { Dama }\end{array}$ & $\begin{array}{l}\text { D }^{\mathrm{a}} \text { Isabel } \\
\text { Manrique de } \\
\text { Lara } \\
\text { Tia tercera } \\
\text { Dama }\end{array}$ & $\begin{array}{r}\mathbf{D}^{\mathrm{a}} \mathbf{M}^{\mathrm{a}} \text { Inés } \\
\text { X conenc } \\
T\end{array}$ & $\begin{array}{l}\text { Manrique } \\
\text { sa de Pare } \\
\text { tercera } \\
\text { Dama }\end{array}$ & $\begin{array}{l}\text { le Lara } \\
\text { les }\end{array}$ & & & $\begin{array}{c}\text { Da Catalina de Velasco y } \\
\text { Ayala } \\
\text { Marquesa del Fresno } \\
\text { Madre } \\
\text { Dama }\end{array}$ \\
\hline & & & 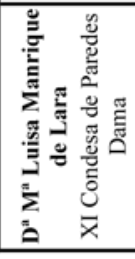 & 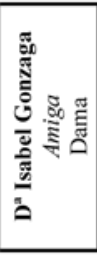 & 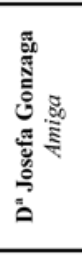 & $\begin{array}{l}\text { Juana de } \\
\text { Córdoba } \\
\text { Condesa de } \\
\text { Chichón } \\
\text { Hermana } \\
\text { Dama }\end{array}$ & \multirow{2}{*}{\multicolumn{2}{|c|}{$\begin{array}{l}\text { Da }^{\mathrm{a}} \text { Luisa de Velasco yTobar, marquesa } \\
\text { de Quirra y Nules } \\
\text { (1637ca.-1674) }\end{array}$}} \\
\hline & & $\begin{array}{l}\text { âa María } \\
\text { cobedo } \\
\text { Criada }\end{array}$ & \multicolumn{2}{|c|}{$\begin{array}{c}\text { Doña Ana Álvarez de } \\
\text { Camargo } \\
\text { Criada }\end{array}$} & \multicolumn{2}{|c|}{$\begin{array}{c}\text { Doña Luisa de } \\
\text { Torres } \\
\text { Criada } \\
\end{array}$} & & \\
\hline
\end{tabular}

Fuente: Elaboración propia. 
Princesa de Esquilache

"Virreina" de Valencia

Marquesa de los Vélez

"Virreina" de

Cerdeña

Esposa de

Alfonso de Calatayud Amiga

\begin{tabular}{|c|c}
\hline & $\mathbf{D}^{\mathbf{a}}$ Mariana \\
$\mathbf{D}^{\mathbf{a}}$ Inés $\mathbf{M}^{\mathbf{a}}$ Chavés $\mathbf{y}$ & Ladrón y Silva \\
Mendoza & Condesa de sinarcas \\
Tercera esposa del IV & casada con del \\
conde del Real & conde de Anna \\
Amiga & Amiga \\
& Dama \\
\hline
\end{tabular}

$D^{\text {a }}$ Guiomar

Coloma y Castelví Mujer del

Gobernador de

Valencia

Amiga 